\title{
Definition of osteoarthritis of the knee for epidemiological studies
}

\author{
T D Spector, D J Hart, J Byrne, P A Harris, J E Dacre, D V Doyle
}

\begin{abstract}
Objectives-There are no agreed criteria for osteoarthritis (OA) of the knee in population studies. The radiographic scoring system of Kellgren and Lawrence has been the system most used in the past and although other methods have been developed, comparisons have not been performed. Therefore these grading systems were compared in radiographs from a general population sample.

Methods-Anteroposterior weightbearing radiographs of 1954 knees from 977 women aged 45-64 years from the Chingford population study were read by a variety of methods, including quantitative measures of minimum joint space, qualitative measures of osteophytes and of joint space, and a qualitative Kellgren and Lawrence global score. All qualitative methods used standardised atlases. Intraobserver and interobserver reproducibility was tested on a subgroup of 100 films using three observers and two readings. Variables were dichotomised at the tenth and second centiles to define OA. Odds ratios were calculated for each method for the association of $O A$ with knee pain, obesity, and with each of the other methods.
\end{abstract}

Results-Most methods had high intraobserver and interobserver reproducibility, except for measurements of lateral joint space. The best predictors of knee pain were the presence of osteophytes and the Kellgren and Lawrence grade. Methods measuring narrowing performed less well, with measurements of lateral joint space being particularly poor. Similar results were achieved in the comparison with obesity and in the comparisons between methods. Conclusions-These data suggest that the presence or absence of a definite osteophyte read by a single observer with an atlas is the best method of defining OA of the knee for epidemiological studies in women. Assessment of narrowing may be better used in evaluating severity.

(Ann Rheum Dis 1993; 52: 790-794)

Osteoarthritis (OA) is a major public health problem in developed countries. For subjects over the age of 45 years most population surveys show that the presence of radiographically determined $\mathrm{OA}$ of the knee varies between 14 and $30 \%$ and increases steadily with age. ${ }^{12}$ Most studies show that the proportion of radiological disease which is symptomatic is between 40 and $80 \%$, and about $50 \%$ of subjects with symptomatic OA of the knee also have an associated disability. ${ }^{3}{ }^{4}$ Despite the enormity of the problem there has been relatively little epidemiological research performed. One reason for this has been the difficulties and problems encountered in defining the disease. Definitions can be based around clinical features, pathological findings, or radiological features. Although they can be used for a variety of purposes, one of the most important is the presence or absence of the disease. Any method for definition should ideally be reproducible, accurate, non-invasive, consistent, and relatively cheap. If appropriately validated, radiographic methods would meet most of these criteria.

For the last 30 years the radiographic grading system of Kellgren and Lawrence ${ }^{5}$ has generally been used for most studies, with its emphasis on the presence of osteophytes. There is some controversy, however, about the importance of osteophytes in populations. It is not clear whether the presence of osteophytes without measurable joint space loss is indeed pathological. Other workers looking at the hand and hip have argued that the separate radiographic features should be recorded and may be more meaningful than an overall composite score such as the Kellgren and Lawrence scale. $^{6}$ To our knowledge an extensive examination of the reproducibility of different radiographic scores and methods in the knee and their relation with knee pain has not been performed in the general population. We therefore examined, in a large population study, the association of different radiographic features with knee pain to determine the best, easily applicable method to define the presence or absence of $\mathrm{OA}$ in the general population for research purposes.

\section{Methods}

A total of 1003 women aged 45-65 years selected from the age and sex register of a large general practice in Chingford, East London, were interviewed and examined as previously described. ${ }^{7}$ Response rates of this group were $78 \%$. These women have been found to be representative of the general population of the United Kingdom in most respects including height, weight, cigarette smoking, and alcohol intake. The majority of the women $(42 \%)$ were of middle class white collar worker status 
(C1), $32 \%$ were group $\mathrm{A} / \mathrm{B}, 17 \% \mathrm{C} 2$, and $8 \%$ $\mathrm{D} / \mathrm{E}$.

Standardised anteroposterior weightbearing radiographs of 1954 knees from 977 women were available for analysis from this population. A single trained observer who was blind to clinical details examined each radiograph for a number of different radiological features and measurements (table 1). Each radiograph was scored for all the features requiring an atlas at one session. Separate sessions were used for the measurement of joint space using a ruler and computer and the data were not available to the reader at the time of qualitative assessment. Films were read blind to symptoms. The features are described in detail in table 1 and included two quantitative measures of minimum joint space [(a) minimum joint space as assessed by ruler to the nearest millimetre (ruler:medial and lateral), and (b) computerised digital image analysis of minimum joint space (computer: medial and lateral) using a video camera and a semiautomated method $^{8}$ ], two qualitative measures of individual features using atlases [(a) joint space narrowing assessed for medial and lateral compartments on a $0-3$ scale $^{9}$ and both compartments combined on a $0-5$ scale $^{10}$ and $(b)$ osteophytes on a $0-3$ scale for both the medial and lateral compartments (osteophytes:medial and lateral) $\left.{ }^{9}\right]$, and finally the

Table 1 Description of the various measurement techniques used

\begin{tabular}{|c|c|}
\hline $\begin{array}{l}\text { Qualitative measures of } \\
\text { minimum joint space } \\
\text { Ruler (medial/lateral) }\end{array}$ & Visual assessment of minimum joint space of medial and lateral \\
\hline Computer (media/lateral) & $\begin{array}{l}\text { compartment measured with clear plastic ruler in millimetres } \\
\text { Digitised assessment of minimum joint space of medial and } \\
\text { lateral compartment measured in millimetres using dedicated } \\
\text { software and video camera }\end{array}$ \\
\hline & \\
\hline Joint space (medial/lateral) & $\begin{array}{l}\text { Visual assessment of medial and lateral narrowing using } \\
\text { separate } 0-3 \text { grades of none, mild, moderate, and severe with an } \\
\text { atlas }\end{array}$ \\
\hline Joint space (combined) & $\begin{array}{l}\text { Visual assessment of overall narrowing using a single five grade } \\
\text { scale to categorise narrowing in both compartments of the joint } \\
\text { using an atlas }\end{array}$ \\
\hline Osteophytes (medial/lateral) & $\begin{array}{l}\text { Visual assessment of medial and lateral osteophytes using } \\
\text { separate } 0-3 \text { grades (none, mild, moderate, and severe) with an } \\
\text { atlas }\end{array}$ \\
\hline $\begin{array}{l}\text { Qualitative global grading } \\
\text { (Kellgren and Lawrence) }\end{array}$ & $\begin{array}{l}\text { Visual assessment using pictures from the standard atlas of } \\
\text { radiographs comparing radiographs to } 0-4 \text { scale }(0=\text { none, } \\
1=\text { doubtful osteophyte, } 2=\text { definite osteophyte, } 3=\text { definite } \\
\text { osteophyte plus narrowing, } 4=0 \text { osteophyte/narrowing } / \\
\text { deformity). As no consensus exists on the exact use of the } \\
\text { Kellgren and Lawrence system for the purposes of this study, a } \\
\text { grade } 2 \text { was taken to indicate the presence of definite } \\
\text { osteophytes and grade } 3 \text { the presence of joint space loss in } \\
\text { addition to the presence of osteophytes }\end{array}$ \\
\hline
\end{tabular}

Table 2 Cutoff levels for definition of osteoarthritis

\begin{tabular}{|c|c|c|c|c|}
\hline Features & $\begin{array}{l}\text { Approx } 10 \% \\
\text { cutoff }\end{array}$ & $\begin{array}{l}\text { Actual } \\
\text { centile (\%) }\end{array}$ & $\begin{array}{l}\text { Approx } 2 \% \\
\text { cutoff }\end{array}$ & $\begin{array}{l}\text { Actual } \\
\text { centile (\%) }\end{array}$ \\
\hline $\begin{array}{l}\text { Ruler (mm) } \\
\text { Medial } \\
\text { Lateral }\end{array}$ & $\begin{array}{l}\leqslant 2 \\
\leqslant 3\end{array}$ & $\begin{array}{r}4 \\
11\end{array}$ & $\begin{array}{l}\leqslant 1 \\
\leqslant 1\end{array}$ & $\begin{array}{l}0 \cdot 6 \\
1 \cdot 6\end{array}$ \\
\hline $\begin{array}{l}\text { Computer (mm) } \\
\text { Medial } \\
\text { Lateral }\end{array}$ & $\begin{array}{l}\leqslant 3 \cdot 6 \\
\leqslant 4\end{array}$ & $\begin{array}{l}10 \\
12\end{array}$ & $\begin{array}{l}\leqslant 3 \\
\leqslant 2 \cdot 4\end{array}$ & $\begin{array}{l}2 \cdot 0 \\
2.5\end{array}$ \\
\hline $\begin{array}{l}\text { Joint space } \\
\text { Medial (0-3) } \\
\text { Lateral }(0-3) \\
\text { Combined }(0-5)\end{array}$ & $\begin{array}{l}\geqslant 1 \\
\geqslant 1 \\
\geqslant 3\end{array}$ & $\begin{array}{r}27 \cdot 0 \\
9 \cdot 4 \\
5 \cdot 1\end{array}$ & $\begin{array}{l}\geqslant 2 \\
\geqslant 2 \\
\geqslant 4\end{array}$ & $\begin{array}{l}1.8 \\
1.5 \\
0.7\end{array}$ \\
\hline $\begin{array}{l}\text { Osteophytes (0-3) } \\
\text { Medial } \\
\text { Lateral }\end{array}$ & $\begin{array}{l}\geqslant 1 \\
\geqslant 1\end{array}$ & $\begin{array}{l}6 \cdot 7 \\
7.7\end{array}$ & $\begin{array}{l}\geqslant 2 \\
\geqslant 2\end{array}$ & $\begin{array}{l}0.5 \\
0.6\end{array}$ \\
\hline Kellgren and Lawrence $(0-4)$ & $\geqslant 2$ & $9 \cdot 0$ & $\geqslant 3$ & $1 \cdot 4$ \\
\hline
\end{tabular}

qualitative global grading scale of Kellgren and Lawrence $\left(0-4\right.$ scale). ${ }^{11}$ All the qualitative methods used standardised published atlases which were referred to routinely during the assessment of each film.

The intraobserver and interobserver reproducibility of the observations was tested on a subgroup of 100 knees selected to include the full range of radiological features. After a combined training session these were read independently three weeks apart by three observers of different levels of experience. All repeat readings were made blind to the original assessments and no markings were left on the radiographs. Because the aim of the study was to assess the best way of defining the presence or absence of OA, all the grades, whether ordinal or continuous, were dichotomised into two groups. Cutoffs for these levels were chosen as approximately the tenth centile of their distribution in the full population sample. This level was chosen as it was similar to the reported levels of radiographic OA (using Kellgren and Lawrence grade $2+$ ) in individual knees in subjects aged 50-70 from different population surveys. ${ }^{2}$ In addition, a second centile cutoff was used to define small numbers with 'severe' disease. Levels of agreement for these dichotomised variables both within observers and between observers (based on the first reading) were summarised by the $\kappa$ statistic. No universal agreement exists on the interpretation of the $\kappa$ statistic, though most workers believe a $\kappa$ value greater than 0.8 to be very good, between 0.6 and 0.8 to be good, and between 0.4 and 0.6 to be average. As part of the Chingford population survey, physical and demographic data were available and details were obtained of body mass index and knee pain, which had been found in previous epidemiological surveys to be strongly associated with the presence of $\mathrm{OA}$ of the knee defined on the basis of symptoms, osteophytes, or joint space. The odds ratios for each of the radiographic features were calculated to provide estimates of the association between knee pain and obesity. The relations between the different radiographic measures were assessed by calculating the odds ratios for the association between each pair of features. As an example, if the odds ratio was 2.0 for a combination of features, this implies that if one feature is present, the odds of the other being present in the same subject is doubled.

\section{Results}

Table 2 gives the cutoffs at the approximate 10 and $2 \%$ level by which OA was defined for each feature. The actual centiles for the chosen cutoff points are also shown and these show some variability, being closer to the $10 \%$ levels for the continuous features and generally lower for the graded features. At the more severe $2 \%$ level the actual centiles were similar. Table 3 summarises the reproducibility of features and gradings within and between the three observers. The intraobserver repeatability for most features was generally good. The computer (medial and lateral) score produced 
a perfect result, the next best results being for the Kellgren and Lawrence grade, presence of osteophytes (medial or lateral) and narrowing (combined), and the worst being the ruler (lateral). The range of interobserver variations are also shown in table 3 . There was generally good agreement between observers for Kellgren and Lawrence grade and the presence of osteophytes, with the computer again producing nearly perfect agreement. Reasonable agreement was found for narrowing (combined). Features that performed poorly were the presence of narrowing, particularly laterally.

Table 4 gives the odds ratios for each feature for knee pain and obesity. The strongest associations with knee pain using the approximate $10 \%$ levels were for osteophytes (medial) (53.4\% with knee pain) and a Kellgren and Lawrence score of $2+(52 \%$ with knee pain). Qualitative features of joint space loss performed less well, particularly lateral joint space $(33.2 \%$ with knee pain). The computer (medial and lateral) score also performed poorly (31-36\% with knee pain). Alteration of the computer program to measure average joint space area rather than the minimum distance did not improve the performance of the score. Similar results were found in association with obesity; osteophytes (lateral and medial) and Kellgren and Lawrence $2+$ were the most strongly associated and the weakest were scores of joint space, whether by ruler, computer, or by qualitative atlas grade. Measures of lateral joint space had an inverse relation with obesity. Analysing the smaller number of subjects with the worst $2 \%$ of all the grades produced broadly similar results, with the Kellgren and Lawrence grade $3+$, medial and lateral osteophytes (grade $2+$ ) again performing well. The major differences compared with the $10 \%$ level results were seen in severe disease; ruler (medial) performed nearly as well as osteophytes (medial and lateral), and combined joint space had the strongest association with knee pain of all the measures.

As expected, the radiographic features correlated with each other and the odds ratios for the tenth centile cutoff are given in table 5 . In general, scores measuring the presence of osteophytes and Kellgren and Lawrence grade performed the best as assessed by the highest odds ratios. These relations were stronger for the second centile cutoffs, but the relative ranking of these was similar.

\section{Discussion}

These data have shown that, using a variety of quantitative and qualitative methods with atlases, good internal consistency can be achieved for a number of different radiographic features, with the most experienced reader

Table 3 Reproducibility of radiographic features (three observers (Obs) read twice based on 100 films). Displayed as $\mathrm{\kappa}$ values (95\% confidence intervals) using $10 \%$ cutoff

\begin{tabular}{|c|c|c|c|c|c|c|}
\hline \multirow[t]{2}{*}{ Features } & \multicolumn{3}{|l|}{ Intraobserver $\mathrm{\kappa}$} & \multicolumn{3}{|l|}{ Interobserver $\mathrm{\kappa}$} \\
\hline & Obs 1 & Obs 2 & Obs 3 & Obs 1 v 2 & Obs $1 \times 3$ & Obs $2 \times 3$ \\
\hline \multicolumn{7}{|l|}{ Ruler (mm) } \\
\hline Medial & $0.86(0.85-0.87)$ & $0.64(0.62-0.66)$ & $0.84(0.83-0.85)$ & $0.43(0.41-0.45)$ & $0.77(0.76-0.78)$ & $0.34(0.33-0.35)$ \\
\hline Lateral & $0.56(0.55-0.57)$ & $0.08(0.07-0.09)$ & $0.49(0.48-0.50)$ & $0.42(0.40-0.44)$ & $0.34(0.33-0.35)$ & $0.21(0.20-0 \cdot 22)$ \\
\hline \multicolumn{7}{|l|}{ Computer (mm) } \\
\hline Medial & $1 \cdot 00$ & 1.00 & $\star$ & $0.95(0.93-0.97)$ & $0.95(0.93-0.97)$ & * \\
\hline Lateral & $1 \cdot 00$ & $1 \cdot 00$ & * & $0.96(0.93-0.99)$ & $0.96(0.93-0.99)$ & $\star$ \\
\hline \multicolumn{7}{|l|}{ Joint space } \\
\hline Medial (0-3) & $0.83(0.82-0.84)$ & $0.41(0.40-0.42)$ & $0.67(0.66-0.68)$ & $0.49(0.48-0.50)$ & $0.60(0.59-0.61)$ & $0.32(0.31-0.33)$ \\
\hline Lateral $(0-3)$ & $0.74(0.73-0.75)$ & $0.48(0.47-0.49)$ & $0.79(0.78-0.80)$ & $0.54(0.53-0.55)$ & $0.30(0.29-0.31)$ & $0.39(0.38-0.40)$ \\
\hline Combined (0-5) & $0.82(0.81-0.83)$ & $0.80(0.79-0.81)$ & $0.83(0.82-0.84)$ & $0.58(0.57-0.59)$ & $0.56(0.55-0.57)$ & $0.50(0.49-0.51)$ \\
\hline \multicolumn{7}{|l|}{ Osteophytes (0-3) } \\
\hline Medial & $0.84(0.83-0.85)$ & $0.49(0.48-0.50)$ & $0.59(0.58-0.60)$ & $0.64(0.63-0.65)$ & $0.71(0.70-0.72)$ & $0.53(0.52-0.54)$ \\
\hline Lateral & $0 \cdot 86(0 \cdot 85-0 \cdot 87)$ & $0.71(0.70-0.72)$ & $0.65(0.64-0.66)$ & $0.69(0.68-0.70)$ & $0.59(0.58-0.60)$ & $0.55(0.54-0.56)$ \\
\hline Kellgren and Lawrence $(0-4)$ & $0.88(0.87-0.89)$ & $0.79(0.78-0.80)$ & $0.66(0.65-0.67)$ & $0.80(0.79-0.81)$ & $0.64(0.63-0.65)$ & $0.56(0.55-0.57)$ \\
\hline
\end{tabular}

${ }^{\star}$ Computer measurements performed by two observers only.

Table 4 Association of radiographic features with knee pain and upper tertile of obesity

\begin{tabular}{|c|c|c|c|c|c|c|}
\hline \multirow[t]{3}{*}{ Feature } & \multicolumn{4}{|l|}{ Knee pain } & \multicolumn{2}{|l|}{ Obesity } \\
\hline & \multicolumn{2}{|l|}{ Tenth centile } & \multicolumn{2}{|l|}{ Second centile } & \multirow{2}{*}{$\begin{array}{l}\text { Tenth centile } \\
\text { Odds ratio } \\
(95 \% \text { CI })\end{array}$} & \multirow{2}{*}{$\begin{array}{l}\text { Second centile } \\
\text { Odds ratio } \\
(95 \% \text { CI) }\end{array}$} \\
\hline & $\begin{array}{l}\text { Odds ratio } \\
(95 \% C I)\end{array}$ & $\begin{array}{l}\text { Percentage with } \\
\text { knee pain }\end{array}$ & $\begin{array}{l}\text { Odds ratio } \\
(95 \% C I)\end{array}$ & $\begin{array}{l}\text { Percentage with } \\
\text { knee pain }\end{array}$ & & \\
\hline $\begin{array}{l}\text { Ruler } \\
\text { Medial } \\
\text { Lateral }\end{array}$ & $\begin{array}{l}2.20(1.35-3.59) \\
1.33(0.90-1.95)\end{array}$ & $\begin{array}{l}42 \cdot 0 \\
30 \cdot 8\end{array}$ & $\begin{array}{l}8.96(2.41-33.2) \\
1.77(0.77-4.07)\end{array}$ & $\begin{array}{l}75 \cdot 0 \\
37 \cdot 5\end{array}$ & $\begin{array}{l}1 \cdot 34(0.65-2 \cdot 74) \\
0.42(0.18-0.96)\end{array}$ & $\begin{array}{r}16.62(4.33-63.8) \\
0.98(0.98-0.99)\end{array}$ \\
\hline $\begin{array}{l}\text { Computer } \\
\text { Medial } \\
\text { Lateral }\end{array}$ & $\begin{array}{l}1.79(1.30-2.48) \\
1.34(0.95-1.89)\end{array}$ & $\begin{array}{l}36 \cdot 4 \\
31 \cdot 0\end{array}$ & $\begin{array}{l}2.94(0.41-20 \cdot 9) \\
2 \cdot 13(1.03-4 \cdot 38)\end{array}$ & $\begin{array}{l}50 \cdot 0 \\
41 \cdot 9\end{array}$ & $\begin{array}{l}0.96(0.57-1.60) \\
0.36(0.17-0.78)\end{array}$ & $\begin{array}{l}0.99(0.99-0.99) \\
0.98(0.97-0.98)\end{array}$ \\
\hline $\begin{array}{l}\text { Joint space } \\
\text { Medial } \\
\text { Lateral } \\
\text { Combined }\end{array}$ & $\begin{array}{l}2 \cdot 10(1.69-2 \cdot 61) \\
1.51(1.08-2 \cdot 09) \\
2.69(1.82-4.01)\end{array}$ & $\begin{array}{l}36 \cdot 5 \\
33 \cdot 2 \\
46 \cdot 5\end{array}$ & $\begin{array}{r}4.52(2.28-8.96) \\
2 \cdot 26(1.09-4 \cdot 69) \\
10.95(3.93-30.5)\end{array}$ & $\begin{array}{l}60 \cdot 0 \\
43 \cdot 3 \\
78 \cdot 6\end{array}$ & $\begin{array}{l}1.72(1.26-2.33) \\
1.02(0.62-1.69) \\
1.01(0.52-1.98)\end{array}$ & $\begin{array}{l}6.39(2.15-18.9) \\
0.98(0.98-0.99) \\
8.09(2.24-29.3)\end{array}$ \\
\hline $\begin{array}{l}\text { Osteophytes } \\
\text { Medial } \\
\text { Lateral }\end{array}$ & $\begin{array}{l}3.73(2 \cdot 60-5 \cdot 35) \\
3.16(2 \cdot 25-4.43)\end{array}$ & $\begin{array}{l}53 \cdot 4 \\
49 \cdot 3\end{array}$ & $\begin{array}{l}8 \cdot 24(4 \cdot 21-16 \cdot 1) \\
4 \cdot 84(2 \cdot 77-8 \cdot 44)\end{array}$ & $\begin{array}{l}72 \cdot 7 \\
61 \cdot 1\end{array}$ & $\begin{array}{l}3 \cdot 22(2 \cdot 10-4 \cdot 96) \\
4 \cdot 63(3 \cdot 14-6 \cdot 81)\end{array}$ & $\begin{array}{r}10 \cdot 13(4 \cdot 23-24 \cdot 3) \\
9 \cdot 54(4 \cdot 19-21 \cdot 8)\end{array}$ \\
\hline Kellgren and Lawrence grade & $3.61(2 \cdot 63-4.95)$ & $51 \cdot 7$ & $9 \cdot 57(4 \cdot 48-20 \cdot 4)$ & $75 \cdot 7$ & $3 \cdot 28(2 \cdot 24-4 \cdot 81)$ & $6 \cdot 16(2 \cdot 08-18 \cdot 3)$ \\
\hline
\end{tabular}

$\mathrm{CI}=$ Confidence interval. 
Table 5 Interrelationship and association of radiographic features using an approximate 10\% cutoff as definition of disease presented as odds ratios (95\% confidence intervals)

\begin{tabular}{|c|c|c|c|c|c|c|c|c|c|}
\hline & $R L$ & $C M$ & $C L$ & FSC & 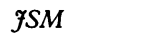 & $\mathscr{F S L}$ & $O M$ & $O L$ & $K \& L$ \\
\hline $\begin{array}{l}\text { Ruler (medial) } \\
\text { Ruler (lateral) (RL) } \\
\text { Computer (medial) (CM) } \\
\text { Computer (lateral) (CL) } \\
\text { Joint space (combined) (JSC) } \\
\text { Joint space (medial) (JSM) } \\
\text { Joint space (lateral) (JSL) } \\
\text { Osteophytes (medial) (OM) } \\
\text { Osteophytes (lateral) (OL) }\end{array}$ & $\begin{array}{l}4 \cdot 6 \\
(2 \cdot 54-8 \cdot 25)\end{array}$ & $\begin{array}{l}12 \cdot 4 \\
(7 \cdot 39-20 \cdot 86) \\
2 \cdot 8 \\
(1 \cdot 79-4 \cdot 53)\end{array}$ & $\begin{array}{l}3 \cdot 1 \\
(1 \cdot 66-5 \cdot 74) \\
13 \cdot 9 \\
(9 \cdot 18-21 \cdot 16) \\
4 \cdot 1 \\
(2 \cdot 77-5 \cdot 98)\end{array}$ & $\begin{array}{l}15 \cdot 0 \\
(9 \cdot 84-22 \cdot 89) \\
5 \cdot 9 \\
(3 \cdot 86-9 \cdot 25) \\
2 \cdot 9 \\
(1 \cdot 72-4 \cdot 82) \\
1 \cdot 9 \\
(1 \cdot 06-3 \cdot 57)\end{array}$ & $\begin{array}{l}8 \cdot 0 \\
(4 \cdot 68-13 \cdot 69) \\
2 \cdot 2 \\
(1 \cdot 52-3 \cdot 14) \\
4 \cdot 3 \\
(3 \cdot 17-5 \cdot 92) \\
2 \cdot 2 \\
(1 \cdot 58-3 \cdot 02) \\
12 \cdot 5 \\
(8 \cdot 29-18 \cdot 69)\end{array}$ & $\begin{array}{l}2 \cdot 6 \\
(1 \cdot 41-4 \cdot 75) \\
10 \cdot 7 \\
(7 \cdot 21-15 \cdot 77) \\
3 \cdot 6 \\
(2 \cdot 45-5 \cdot 32) \\
7 \cdot 4 \\
(5 \cdot 05-10 \cdot 75) \\
5 \cdot 2 \\
(3 \cdot 41-7 \cdot 82) \\
6 \cdot 6 \\
(4 \cdot 79-9 \cdot 18)\end{array}$ & $\begin{array}{l}5 \cdot 1 \\
(2 \cdot 83-9 \cdot 01) \\
0 \cdot 5 \\
(0 \cdot 22-1 \cdot 34) \\
1 \cdot 8 \\
(1 \cdot 08-3 \cdot 02) \\
1 \cdot 0 \\
(0 \cdot 56-1 \cdot 93) \\
4 \cdot 8 \\
(3 \cdot 07-7 \cdot 74) \\
2 \cdot 9 \\
(2 \cdot 03-4 \cdot 15) \\
2 \cdot 2 \\
(1 \cdot 36-3 \cdot 55)\end{array}$ & $\begin{array}{l}2 \cdot 9 \\
(1 \cdot 57-5 \cdot 50) \\
1 \cdot 2 \\
(0 \cdot 67-2 \cdot 29) \\
1 \cdot 2 \\
(0 \cdot 70-2 \cdot 09) \\
0 \cdot 8 \\
(0 \cdot 44-1 \cdot 56) \\
4 \cdot 4 \\
(2 \cdot 77-6 \cdot 90) \\
2 \cdot 6 \\
(1 \cdot 84-3 \cdot 62) \\
2 \cdot 6 \\
(1 \cdot 65-3 \cdot 95) \\
25 \cdot 0 \\
(16 \cdot 6-37 \cdot 7)\end{array}$ & $\begin{array}{l}2 \cdot 9 \\
(1 \cdot 63-5 \cdot 33) \\
0 \cdot 9 \\
(0 \cdot 49-1 \cdot 75) \\
1 \cdot 6 \\
(0 \cdot 98-2 \cdot 51) \\
1 \cdot 3 \\
(0 \cdot 78-2 \cdot 17) \\
4 \cdot 0 \\
(2 \cdot 58-6 \cdot 29) \\
3 \cdot 5 \\
(2 \cdot 53-4 \cdot 75) \\
3 \cdot 1 \\
(2 \cdot 07-4 \cdot 58) \\
56 \cdot 7 \\
(36 \cdot 4-88 \cdot 4) \\
72 \cdot 4 \\
(46 \cdot 7-112 \cdot 1)\end{array}$ \\
\hline
\end{tabular}

scoring highest. The only feature that was difficult to measure reproducibly was lateral joint space, either by ruler or by using an atlas for grading. As expected, interobserver reproducibility was poorer but nevertheless reasonable for most features. Thus, with the possible exception of narrowing of the lateral compartment of the knee, most of the features examined were reproducible.

The next question we asked was which of these features best defined the clinical entity known as OA of the knee. Unfortunately, although a definition has been proposed for clinical trials, ${ }^{12}$ its use is controversial and in populations there is no gold standard of OA with which to test our measures. ${ }^{13}$ Most clinicians would, however, agree that for a radiographic sign to be relevant to the disease, knee pain should be associated with the sign. Thus our primary objective was to compare the features with the presence or absence of knee pain. The strongest associations with knee pain were with the presence of osteophytes, either on their own or as a feature of the Kellgren and Lawrence scale. Our interpretation of the Kellgren and Lawrence grade $2+$ was essentially the same as that of the medial or lateral osteophyte (grade 1), only differing in that for the former either compartment could be affected and a slightly different atlas picture was used. The features showing the weakest associations with knee pain were those using measurement of joint space, particularly those measurements of lateral compartment joint space whether by ruler, computer, or atlas. Measurements of medial compartment space, by all methods, performed similarly with respect to knee pain but were all, nevertheless, inferior to scores based on osteophytes. The lack of a good association between narrowing and knee pain is surprising given the excellent reproducibility of the ruler and computer measurements. Choosing an approximate tenth centile cutoff for graded variables resulted in a different true prevalence based on some features than others. This might have biased the comparisons. The second centile cutoffs, however, produced less variation and the results were comparable with those produced by the tenth centiles, suggesting this was not an important bias.
This paper only assessed anteroposterior knee films which are routinely used in population surveys. If lateral or skyline views were obtained in addition, extra information on the radiological features might have altered some of the associations. For example, it is possible that the good performance of the osteophyte on anteroposterior films is due to a strong association of patellofemoral disease and this is an area where further work would be useful. Nevertheless, these results indicate that the presence or absence of a definite osteophyte is the most appropriate method of defining OA for epidemiological purposes. The exact site of the osteophyte does not appear to matter as medial and lateral osteophytes performed similarly.

The role of the osteophyte in OA is controversial, with several workers believing that osteophytes are merely a reflection of age and not associated with any of the clinical symptoms of OA. There are few reported data to support or refute this argument. The major study quoted is by Hernborg and Nilsson who retrospectively studied a large group of knee radiographs 10 years apart, all of which had bony sclerosis. ${ }^{14}$ Thirty five of 107 knees with osteophytes alone progressed to structural changes. Other population based studies have shown that osteophytes, even when asymptomatic, are associated with an increased risk of disability and loss of function several years later. ${ }^{3}{ }^{4}$ The good performance of the Kellgren and Lawrence system in this study was probably due to our interpretation of the essential component being the presence of the osteophyte. The major problem of the Kellgren and Lawrence method is the ambiguity of interpretation of each grade as a number of different descriptions by the original workers accompany the atlases..$^{15}$ These problems have allowed workers to define OA in different ways while maintaining that they had used standard criteria. For example, one version defines grade II for knees as 'the presence of definite osteophytes with minimal joint space narrowing' and a later version 'definite osteophytes but the joint space is unimpaired'. In addition, the films chosen for the atlases do not conform to the written descriptions. If defined clearly, as in this study, it will remain 
a powerful epidemiological tool which will allow comparison of populations and with previous surveys.

The use of a standardised atlas is likely to be important in obtaining good results. In all our readings the reference pictures were used at all times with the atlas kept open at the appropriate page.

It is likely that the role of the osteophyte is different at different sites of the body. Croft et al performed a similar analysis and evaluation of radiographic measures in OA of the hip in a large population of men and found that measurement of the minimum joint space was the best single index of $\mathrm{OA}$, the presence of osteophytes being less important. ${ }^{6}$

The performance of the features analysed in this study may be different in older women or in men and it is not necessarily the best way to examine severity or progression. It is possible that for severity and progression the assessment of joint space may be more useful and it remains to be seen which method fulfils this role. Our results suggest, however, that the reproducibility and interpretation of the lateral joint space of the knee is unreliable and attention should be focused on the medial compartment. Some support for a role of joint space in assessing severity arose from our data when we used a severe $2 \%$ cutoff to determine OA. In this the Kellgren and Lawrence grade $3+$, osteophytes (grade 2), joint space (combined) and ruler (medial) all performed well, with more than $72 \%$ of subjects being identified as symptomatic. In summary, our data support the use of the definite osteophyte (defined by atlas) to define the presence or absence of OA of the knee for epidemiological studies in population samples.

We thank the staff at Chingford Hospital for their cooperation in this study and the general practitioners and patients at the
Highams Park Medical Partnership. This study was partly funded by a grant from the Joint Research Board of $S$ Bartholomew's Hospital. We also thank Angela Chamberlain for her help in reviewing the radiographs, Dr David Coggon, Dr Cyrus Cooper, and Dr Peter Croft for their comments on the manuscript, the UK OA Definition Study Group for the discussion which stimulated this paper, and Jane Melbourne for her typing skills.

1 Van Saase J L C M, Van Romunde L K S, Cats A, Vandenbroucke J P, Valkenburg H A. Epidemiology of osteoarthritis: Zoetermeer survey. Comparison of radiological osteoarthritis in a Dutch population with that in 10 other populations. Ann Rheum Dis 1989; 48: 271-80.

2 Spector T D, Hart D J. How serious is knee osteoarthritis? Ann Rheum Dis 1992; 51: 1105-6.

3 Davis M A, Ettinger W H, Neuhaus J M, Mallon K P. Knee $O A$ and physical functioning: evidence from the NHANES epidemiologic follow-up study. I Rheumatol NHANES epidemi

4 Hochberg M C. Epidemiologic association of pain in osteoarthritis of the knee: data from the National Health and Nutrition Examination Survey and the National Health and Nutrition Examination. Vol. 1, Epidemiologic follow-up survey. Semin Arthritis Rheum 1989; 18 (suppl 2): 4-9.

5 Kellgren J K, Lawrence J S. Radiological assessment of osteoarthritis. Ann Rheum Dis 1957; 16: 494-501.

6 Croft P, Cooper C, Wickham C, Coggon D. Defining osteoarthritis of the hip for epidemiologic studies. Am $尹$ Epidemiol 1990; 132: 514-22.

7 Hart D J, Spector T D. The relationship of obesity, fat distribution and osteoarthritis in women in the general population: the Chingford study. I Rheumatol 1993; 20: 331-5.

8 Dacre J E, Huskisson E C. The automatic assessment of knee radiography in OA using digital image analysis. $\mathrm{Br}$ f Rheumatol 1989; 28: 506-10.

9 Spector T, Cooper C, Cushnaghan J, Hart D J, Dieppe P A. A radiographic atlas of knee osteoarthritis. London: A. A radiographic atlas of

10 Dacre J E, Huskisson E C. A simple scoring system for knee osteoarthritis based on joint space loss. Eur $\mathcal{F}$ Rheumatol osteoarthritis based on join

11 Kellgren J K, Lawrence J S. The epidemiology of chronic rheumatism. Atlas of standard radiographs. Vol 2. Oxford: Blackwell Scientific, 1963.

12 Altman R, Asch E, Bloch D, et al. Development of criteria for classification and reporting of osteoarthritis. Arthritis Rheum 1986; 29: 1039-49.

13 McAlindon T, Dieppe P A. Osteoarthritis: definitions and criteria. Ann Rheum Dis 1989; 48: 531-2.

14 Hernborg J, Nilsson B G. The relationship between osteophytes in the knee joint, osteoarthritis and aging. Acta Orthop Scand 1973; 44: 69-74.

15 Spector T D, Cooper C. Radiographic assessment of osteoarthritis in population studies: whither Kellgren and Lawrence? Osteoarthritis and Cartilage. In press. 